\title{
Smoking cessation interventions for patients with heart disease
}

\author{
Sally S Foland
}

Smoking is major risk factor for cardiovascular disease; $40 \%$ of cardiovascular deaths are attributed to smoking. ${ }^{1}$ For individuals who have been smokers and who experience a cardiac event, quitting reduces the risk of a recurrent event by $50 \%$.

In July 1996, Kaiser Permanente-Colorado implemented the MULTIFIT cardiac rehabilitation and risk reduction program. The MULTIFIT program is a nurse case managed, home based model with risk reduction interventions for smoking cessation, diet management, exercise, and lipid management with drug treatment. It is the result of a research study which took place from 1988 to 1991 conducted by Stanford University and Northern California Kaiser Permanente. ${ }^{2}$ Candidates of the program include individuals recently hospitalised for myocardial infarction, angioplasty, coronary bypass surgery, or angina. Nurses carry caseloads of 150-200 patients and follow patients for 12 months, primarily through telephone and mail encounters and limited visits. Use of a computer software program allows tracking of patient data. The cost of the MULTIFIT program is $\$ 500$ or less per patient, compared with $\$ 1500$ to $\$ 2500$ per patient if the patient is referred to a community cardiac rehabilitation program. Published results showed improved outcomes for patients over "usual care" including higher smoking cessation rates, improved lipids and exercise tolerance, and high patient and physician satisfaction.

The inpatient smoking cessation intervention includes strong advice to quit from the physician, and a predischarge smoking cessation counselling session. The patients complete questionnaires giving information about their interest in quitting smoking, their level of addiction, and their confidence to remain non-smokers. The nurse uses the patients' responses to adapt counselling to the patients' needs and readiness to quit, to assess the need for pharmacologic treatment, and to screen for depression.

Outpatient telephone follow up is more frequent for patients who smoked before their cardiac event and focuses on relapse prevention. Patients may come in for a visit if they are struggling with staying smoke free and they are referred to cessation programs if relapse occurs.

One year after implementing the MULTIFIT program in our region an evaluation showed that $26 \%(50 / 199)$ of patients who had been enrolled in the program for at least six months had smoked in the six months before their hospitalisation. Of those who smoked, $50 \%$ had quit, $28 \%$ had "tried to quit and relapsed" within the first three months, and $22 \%$ returned to smoking upon discharge. Of those who quit and relapsed, $90 \%$ intended to quit within six months. Now, three years since the program was implemented, our MULTIFIT program is experiencing smoking cessation rates of $60 \%$ at one year. This compares with $70 \%$ in the research study and $64 \%$ in the pilot studies that were carried out in Northern California Kaiser Permanente subsequent to the study.

Challenges include achieving adequate staffing levels to meet patient volume, and short length of stays in the hospital. Things which have made this program successful include: an automatic referral policy to cardiac rehabilitation, a close relationship with the health education department and the smoking cessation programs, and implementation of the Agency for Health Care Policy and Research guideline throughout our organisation. ${ }^{3}$

In summary, a program such as the MULTIFIT cardiac risk reduction and rehabilitation program, with modifications to meet the needs of your organisation and setting, can be an effective approach to give cardiac patients the support they need to quit smoking.

Thanks to Stacy Brennan, RN, Cardiac Case Coordinator, for her contribution to managing the operations for this program.

1 Miller M, Vogel R. The practice of coronary disease prevention. Baltimore: Williams \& Williams, 1996:139-58.

2 Debusk RF, Miller NH, Superko HR, et al. A case management system for coronary risk factor modification after acute myocardial infarction. Ann Intern Med 1994; 120:721-9.

3 Fiore MC, Bailey WC, Cohen SJ, et al. Smoking cessation. Clinical Practice Guideline No. 18. Rockville Maryland: US Department of Health and Human Services, Public Health Service, Agency for Health Care Policy and Research, April 1996. (AHCPR Publication No 96-0692.) 